\title{
Factors affecting location failure of GPS collars fitted to African leopards (Panthera pardus)
}

\author{
Lourens H. Swanepoel $^{1 *}$, Fredrik Dalerum ${ }^{1,2}$ \& Wouter van Hoven ${ }^{1}$ \\ ${ }^{1}$ Centre for Wildlife Management, University of Pretoria, Pretoria, 0002 South Africa \\ ${ }^{2}$ Mammal Research Institute, Department of Zoology and Entomology, University of Pretoria, Pretoria, 0002 South Africa
}

Received 25 September 2009. Accepted 11 February 2010

\begin{abstract}
Recent technological advances in Global Positioning system (GPS) technology have generated an increase in the use of GPS collars fitted to wild animals to track their movements. GPS units are advantageous compared to other methods of remote tracking of animals in that the have the ability to gather large quantities of spatial data that may be accessed remotely. However, animal behaviour, topography, vegetation, and seasonality could all influence GPS acquisition success and therefore bias results from GPS technology. Here we analyse temporal and seasonal patterns associated with GPS acquisition failures in five GPS collars fitted to leopards (Panthera pardus) in the Waterberg region of South Africa. Of 6565 attempted GPS acquisitions, 19\% (1236) failed with the location failure rate of individual collars ranging from 15-29\%. Single failed attempts accounted for the majority of location failures, suggesting that failure was caused by temporary blockage to satellites. Failure rates were significantly higher during the day and there were indications that they were higher during the wet season than in the dry season. Failures were also clustered in space for some individual animals. Our results suggest that temporal patterns of animal behaviour and habitat choice influence the probability of GPS location failures in this species. We therefore suggest that potential biases should be accounted for when using GPS data to analyse movement and habitat selection in this and similar carnivore species.
\end{abstract}

Key words: animal movement, carnivore, GPS collars, habitat selection, methodological error, remote tracking.

\section{INTRODUCTION}

For over half a century, remote monitoring and tracking of animal movements have been a cornerstone for wildlife research (Priede \& Swift 1992). Three distinct types of remote monitoring of wildlife are currently in use; (i) Very High Frequency (VHF) radio telemetry, (ii) satellite based telemetry (Platform Transmitter Terminal, PTT), and (iii) Global Positioning System (GPS) tracking. VHF and PTT techniques differ from GPS-based approaches in that the unit fitted to the animal contains only a transmitter and the geographic location of this transmitter is determined by tracking either directly by personnel or by satellites. GPS systems, on the other hand, triangulate the position within the unit fitted to the animal using information from the United States military Global Navstar constellation of satellites (Douglas-Hamilton 1998). Advantages of GPS collars compared with collars containing VHF radio or satellite telemetry systems is that they do not need to be actively tracked,

\footnotetext{
*To whom correspondence should be addressed.
} E-mail: s96162831@tuks.co.za they have the ability to store spatial data in the collar unit for later download and have a higher spatial accuracy (Gau et al. 2004).

Since GPS collars rely on satellites to calculate their geographic locations, factors that impede a collar's view of the sky will influence GPS performance (D'eon et al. 2002). Animal activity (Ron et al. 1996), sampling interval (Moen et al. 2001), vegetation (Rempel et al. 1995), topography (Gau et al. 2004; Cain et al.2005), and collar orientation (D'eon \& Delparte 2005) have all been shown to influence location accuracy and acquisition success. For instance, in several studies in boreal forests, GPS performance declined with increasing tree height, canopy cover, tree density and basal area, and improved as the interval between fixes decreased (Rempel et al. 1995, Moen et al. 2001; Janeau et al. 2004). Therefore, the success of achieving GPS fixes may not be random and such non-random error could bias results from GPS technology (D'eon et al. 2002). For example, Merrill \& Mech (2003) reported that missing GPS locations could alter the description of movement 
Table 1. Summary of GPS collar performance and number of days leopard were tracked as well as nearest neighbour statistics for the last successful geographic location point preceding each failure.

\begin{tabular}{|c|c|c|c|c|c|c|c|c|c|}
\hline \multirow[b]{2}{*}{ Animal } & \multirow[b]{2}{*}{ Sex } & \multicolumn{2}{|c|}{ Date } & \multicolumn{3}{|c|}{ Location } & \multirow[b]{2}{*}{$R$} & \multirow[b]{2}{*}{ Z } & \multirow[b]{2}{*}{$P$} \\
\hline & & Collared & Stopped & Attempted & Failed & $\begin{array}{c}\text { Failure rate } \\
(\%)\end{array}$ & & & \\
\hline$A$ & $\mathrm{~F}$ & 15 Oct 04 & 15 Apr 05 & 874 & 255 & 29.18 & 1 & $<0.01$ & $>0.999$ \\
\hline$B$ & $\mathrm{~F}$ & 1 July 05 & 27 Aug 05 & 270 & 42 & 15.56 & 0.39 & 14 & $<0.001$ \\
\hline C & $F$ & 9 Aug 05 & 20 Feb 07 & 2628 & 413 & 15.72 & 0.72 & 7.26 & $<0.001$ \\
\hline$D$ & M & 5 Feb 05 & 10 Mar 05 & 174 & 27 & 16.00 & 1 & $<0.01$ & $>0.999$ \\
\hline$E$ & M & 26 June 05 & 20 Feb 07 & 2793 & 526 & 18.83 & 0.68 & 11.8 & $<0.001$ \\
\hline Total & & & & 6565 & 1236 & 18.83 & & & \\
\hline
\end{tabular}

patterns, and Frair et al. (2004) demonstrated that even small losses of data can result in biased quantifications of animal resource use. Missing data therefore remain an important potential source of error and bias in GPS telemetry (D'eon \& Delparte 2005). Researchers should be aware of these factors in order to account for and rectify any biases they may cause (Frair et al. 2004; Janeau et al. 2004).

In this study we report on factors affecting the failure of GPS fixes in five GPS collars fitted to leopards (Panthera pardus) in a mountainous area of the Waterberg region, Limpopo province, South Africa.

\section{METHODS}

We conducted the study on game ranches in the Waterberg Mountains, Limpopo province, South Africa. Topographical features include rugged mountain slopes, steep-sided riverine areas, flat plateaus and valley bottoms. Vegetation is classified as Waterberg Mountain Bushveld (Mucina \& Rutherford 2006).

We captured two male and three female leopards using baited cage-traps with drop-door mechanisms (de Wet 1993). Caged leopards were anaesthetized by a wildlife veterinarian with a mixture of tiletamine $\mathrm{HCL}$ and zolazepam HCL (Zoletil; Virbac Animal Health, Halfway House, South Africa) at a dose of $4-5 \mathrm{mg} / \mathrm{kg}$ of estimated leopard body weight. We left anaesthetized leopards to recover in the cage-trap at the capture site. We conducted the research under University of Pretoria Animal Use and Care Committee ethics clearance protocol A022-06 and Limpopo provincial government leopard permit capture number CPM-004-00006.

We fitted leopards with GPS collars with a GSM uplink (African Wildlife Tracking, Pretoria, South Africa). The collars weighed $650 \mathrm{~g}$, which is approximately $2 \%$ of the body weight of adult leopards. Collars were set to record GPS locations every 5 hours, which were stored in the collar's non-volatile memory. Spatial data were transmitted to a website via a GSM network whenever the collared animal entered an area with GSM coverage. GPS units were set to search for a maximum of 180 seconds to acquire a minimum of three satellites needed to obtain a GPS location. GPS location data were downloaded from the internet every morning during the study. Two collars delivered GPS locations for over 500 days while the remaining three collars stopped functioning after 181,57 and 35 days, respectively (Table 1 ). It is not known if these three leopards were killed by ranchers or if the collars failed.

Since the collars were programmed to give independent sample points in time, we could not reliably use existing locations to analyse the geographic location of failures. However, we crudely approximated the spatial distribution of failures throughout each animal's home range by the last location point before each failure, and tested if the distributions of these points differed from a uniform spatial distribution following Clark \& Evans (1956). We used a mixed generalized linear model with a log link function and Poisson error structure to test if season (defined as dry (AprilNovember) and wet (December-March)), and sex of the study animal affected the number of consecutive failures. In the model, we used the frequency of blocks of failures (each block containing the number of consecutive failures) as response variable, and fitted season, sex and an interaction term between these variables as fixed factors. We added animal identity as a random factor to account for non-independence within animals. To evaluate the effects of season (defined as above), sex and time of day on the probability of location failure, we 


\section{Female \\ (Animal A)}

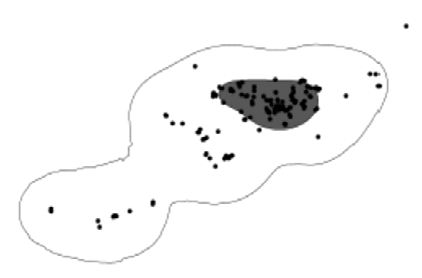

Male

(Animal D)

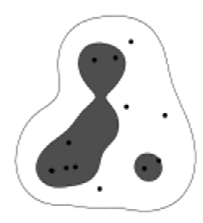

Female (Animal B)

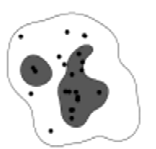

\section{Male}

(Animal E)

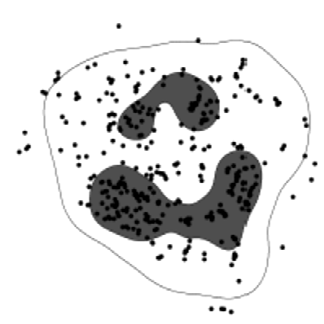

Female (Animal C)

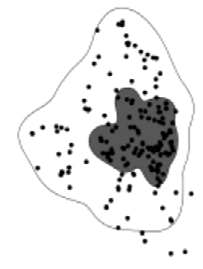

95\% Utilization intensity

$50 \%$ Utilization intensity

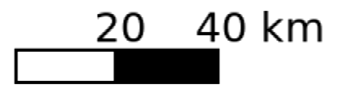

Fig. 1. Spatial distributions of the last successful location prior to each failure for all study animals.

constructed a mixed generalized linear model with a logit link and binomial error structure using each location attempt, coded as either failed or successful, as response variable. In the model, we fitted sex, season and hour of day as fixed variables, including all interaction terms. We added individual as a random factor to account for interdependence within individual animals. Hour of day was factorised in the model since 24-hour time data is not appropriate to analyse as a linear variable (Batschelet 1981). To evaluate the explicit effect of time of day, we constructed separate models for males and females, and compared each hour against the nominal reference hour, which in our case was set to midnight. We fitted all models using penalised quasi likelihood and evaluated fixed effects and coefficients using Wald $F$ and $t$ statistics, respectively (Bolker et al. 2008). Statistical analysis was conducted using $R$ version 2.10.1 ( $R$ : A language and environment for statistical computing; R Foundation for Statistical Computing, Vienna, Austria).

\section{RESULTS}

The failure rate for all collars was $19 \%$ of attempted GPS fixes, with individual failure rates ranging from 15-29\% (Table 1). The spatial distribution of the last location before each failure was signifi- cantly more clustered than a random distribution for all animals (Table 1) except one male and one female (Fig. 1).

Single fix failures were most common ( $59 \%$ of all failed fixes), followed by two consecutive failures $(19 \%)$, three consecutive failures $(8 \%)$, and four consecutive failures (4\%). More than four consecutive failures accounted for $10 \%$ of all failures. The maximum number of consecutive failures ranged from 5 to 37 . There were no significant effects of the sex of the animal $\left(F_{1,3}=4.24, P=0.14\right)$ nor season $\left(F_{1,758}=1.55, P=0.21\right)$ on the distribution of number of successive failures. There was also no significant interaction effect between these two variables $\left(F_{1,758}=0.13, P=0.71\right)$. There was a significant interaction effect of sex and time of day on the probability of location failure $\left(F_{23,6521}=2.68\right.$, $P<0.001$ ) and a trend for a higher probability of failure in the wet (failure rate $21.7 \pm 7.6 \%$ ) compared to the dry season (failure rate $17.0 \pm 3.4 \%$ ) $\left(F_{1,6521}=2.81, P=0.09\right.$, Fig. 2a). None of the other fixed terms significantly explained the probability of location failure (Table 2).

For males, the probability of failure between 08:00 and 18:00 and was significantly higher compared to midnight, and for females the probability of failure was significantly lower between 13:00 and 15:00 compared to midnight (Fig. 2b). 
(a)
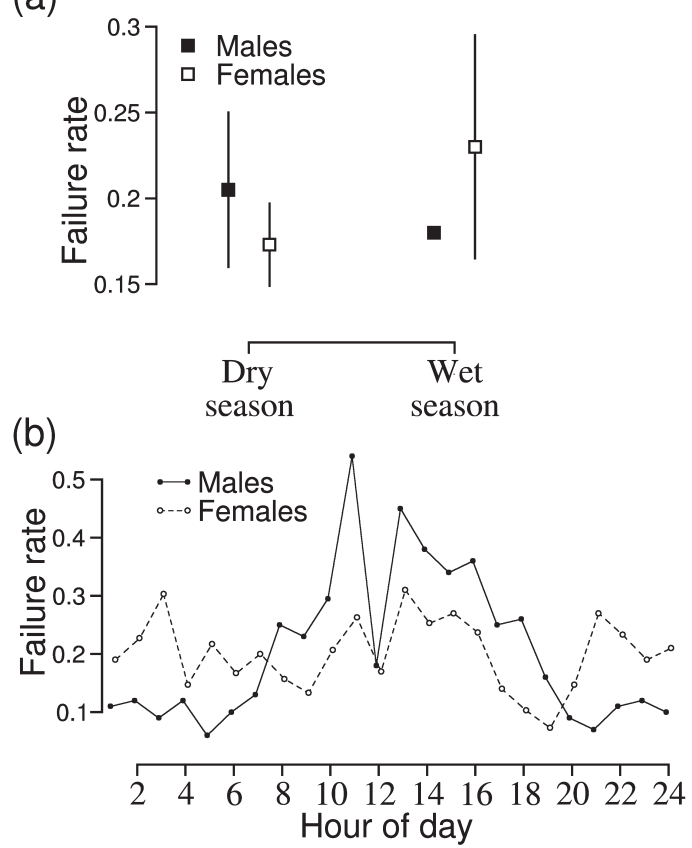

Fig. 2. Failure rates of GPS location points in collars fitted to two male and three female leopards over dry (AprilNovember) and wet (December-March) seasons (a) as well as over all hours of the day (b). Figures present mean values calculated on individual means \pm 1 S.E. (a).

For females, there was also a trend for a lower probability of failure between $04: 00$ and 06:00 compared to midnight (Table 3).

\section{DISCUSSION}

The GPS failure rates reported here are within the range of what has been reported in some other studies on similar species (e.g. Gau et al. 2004:

Table 2. Result from generalized linear mixed model on the effects of sex, season, and time of day on the probability of location failure.

\begin{tabular}{lrrr}
\hline Term & $F$ & d.f. & $P$ \\
\hline Season & 2.815 & 1,6521 & 0.093 \\
Sex & 1.061 & 1,3 & 0.379 \\
Time of day & 1.403 & 23,6521 & 0.095 \\
Season $\times$ Sex & 0.003 & 1,6521 & 0.953 \\
Season $\times$ Time of day & 0.733 & 23,6521 & 0.816 \\
Sex $\times$ Time of day & 2.681 & 23,6521 & $<0.001$ \\
Season $\times$ Sex $\times$ & 1.230 & 23,6521 & 0.206 \\
Time of Day & & & \\
\hline
\end{tabular}

$22-45 \%$ for GPS collars fitted to bears (Ursus spp.), Anderson \& Lindzey 2003: 17-40\% for cougars (Puma concolor), Janeau et al. 2004: $7.4-27 \%$ for red deer), but substantially higher than a $3 \%$ failure rate that Rahimi \& Owen-Smith (2007) reported for GPS collars fitted to sable antelope (Hippotragus niger) in the Kruger National Park. Sable antelope prefer open, flat woodland (Skinner \& Chimimba 2005), and their lower failure rate could therefore be linked to a lower interference from vegetation and topography (Cain et al. 2005) and animal behaviour (D'eon \& Delparte 2005). This exemplifies the importance of habitatrelated variables and animal behavour for the accuracy of GPS technology.

Single failures were more common than two or several consecutive failures, suggesting that most failures had been caused by temporary interference with the GPS collar's view to satellites. Animal activity may play a significant part in GPS collar fix failures (D'eon \& Delparte 2005) and if an animal lies down it can obstruct the view to the sky that will influence the ability of the GSP to take a location fix. For example, black bears (Ursus americanus) that dig while foraging have a different fix rate than non-foraging bears (Obbard et al. 1995). Similarly, when a leopard is prostrate, the collar's ability to acquire a GPS signal may be reduced. Leopards are rarely stationary for periods longer than 20 minutes (Bailey 1993), which supports that resting activity will only momentarily interfere with GPS location attempts. However, in two female leopards four or more failed consecutive fixes were prevalent. This suggests that the animals had stayed in an area which totally blocked the GPS ability to locate satellites for a longer period. This could occur if females give birth or have young confined to a den (Bailey 2005), which leopards often do in crevasses, caves, or areas with very dense vegetation (Bailey 1993; Skinner \& Chimimba 2005).

We found a higher probability of failure during the day compared to midnight; however, the diel patterns of failures differed between males and females. This finding is most likely caused by a combination of leopard behaviour and the terrain they use during specific hours of the day. Both male and female leopards use daytime resting sites (Skinner \& Chimimba 2005), which in the Waterberg normally comprise mountain ridges or caves which may interfere with satellite acquisition (Cain et al. 2005). The difference between the sexes is likely linked to different activity patterns 
Table 3. Probabilities for the difference in the likelihood of failure between hours of the day and midnight for male and female leopards. Data are from generalized linear mixed models with a logit link and binomial error structure, and statistical inference was assessed using a wald $t$-statistic.

\begin{tabular}{lclll}
\hline Hour of day & $\begin{array}{c}\text { Odds ratio } \\
(\mathrm{OR})^{*}\end{array}$ & S.E. OR & $t$ & $P$ \\
\hline
\end{tabular}

\begin{tabular}{|c|c|c|c|c|}
\hline \multicolumn{5}{|c|}{ Males } \\
\hline 1 & 0.203 & 0.414 & 0.491 & 0.623 \\
\hline 2 & 0.203 & 0.414 & 0.491 & 0.623 \\
\hline 3 & -0.250 & 0.452 & -0.553 & 0.580 \\
\hline 4 & 0.164 & 0.420 & 0.391 & 0.696 \\
\hline 5 & -0.314 & 0.431 & -0.729 & 0.466 \\
\hline 6 & 0.041 & 0.426 & 0.096 & 0.924 \\
\hline 7 & 0.164 & 0.420 & 0.391 & 0.696 \\
\hline 8 & 1.044 & 0.373 & 2.798 & 0.005 \\
\hline 9 & 0.939 & 0.378 & 2.483 & 0.013 \\
\hline 10 & 1.498 & 0.369 & 4.063 & 0.000 \\
\hline 11 & 2.343 & 0.380 & 6.164 & 0.000 \\
\hline 12 & 1.175 & 0.359 & 3.271 & 0.001 \\
\hline 13 & 1.916 & 0.359 & 5.342 & 0.000 \\
\hline 14 & 1.628 & 0.362 & 4.496 & 0.000 \\
\hline 15 & 1.567 & 0.351 & 4.458 & 0.000 \\
\hline 16 & 1.564 & 0.362 & 4.321 & 0.000 \\
\hline 17 & 1.045 & 0.375 & 2.785 & 0.005 \\
\hline 18 & 1.057 & 0.375 & 2.815 & 0.005 \\
\hline 19 & 0.457 & 0.401 & 1.139 & 0.255 \\
\hline 20 & 0.167 & 0.398 & 0.421 & 0.674 \\
\hline 21 & -0.346 & 0.464 & -0.745 & 0.456 \\
\hline 22 & 0.060 & 0.426 & 0.141 & 0.888 \\
\hline 23 & 0.144 & 0.420 & 0.343 & 0.731 \\
\hline \multicolumn{5}{|c|}{ Females } \\
\hline 1 & -0.033 & 0.328 & -0.102 & 0.919 \\
\hline 2 & -0.080 & 0.283 & -0.284 & 0.776 \\
\hline 3 & 0.076 & 0.279 & 0.271 & 0.786 \\
\hline 4 & -0.747 & 0.322 & -2.319 & 0.021 \\
\hline 5 & -0.412 & 0.304 & -1.355 & 0.175 \\
\hline 6 & -0.455 & 0.303 & -1.500 & 0.134 \\
\hline 7 & -0.295 & 0.295 & -1.000 & 0.317 \\
\hline 8 & -0.320 & 0.295 & -1.084 & 0.278 \\
\hline 9 & -0.295 & 0.295 & -1.000 & 0.317 \\
\hline 10 & 0.086 & 0.281 & 0.306 & 0.760 \\
\hline 11 & 0.218 & 0.272 & 0.802 & 0.423 \\
\hline 12 & -0.071 & 0.282 & -0.250 & 0.803 \\
\hline 13 & 0.267 & 0.254 & 1.051 & 0.293 \\
\hline 14 & 0.351 & 0.271 & 1.294 & 0.196 \\
\hline 15 & 0.176 & 0.277 & 0.638 & 0.524 \\
\hline 16 & 0.053 & 0.278 & 0.189 & 0.850 \\
\hline 17 & -0.520 & 0.306 & -1.700 & 0.089 \\
\hline 18 & -0.770 & 0.328 & -2.350 & 0.019 \\
\hline 19 & -0.655 & 0.318 & -2.059 & 0.040 \\
\hline 20 & -0.288 & 0.295 & -0.975 & 0.330 \\
\hline 21 & 0.004 & 0.282 & 0.014 & 0.989 \\
\hline 22 & -0.131 & 0.286 & -0.457 & 0.647 \\
\hline 23 & -0.254 & 0.293 & -0.869 & 0.385 \\
\hline
\end{tabular}

*Odds ratios describes the relative likelihood that a failure would occur for a specific hour of day compared to a reference level, which in our case was set to midnight. between males and females. Activity of female leopards abruptly increases around dusk and dawn (Grimbeek 1992; Bailey 1993). Since leopards usually travel on well established paths with less dense vegetation (Bailey 1993), we suggest that the low failure rate for females around dusk and dawn is caused by this temporary increase in activity. We suggest that the generally lower failure rate of males during the night similarly can be explained by a higher activity level in males compared to females (Bailey 1993). Apart from short-term temporal variation in failure rates, we also found indications that time of year may affect the probability of GPS failure, with a higher probability of fix failure in the wet season compared to the dry. This trend can be explained by the increased leaf mass and vegetation density during the wet season, which concurs with other studies (Rempel et al. 1995). This effect was, however, less evident in the males, which suggest that the overall higher activity of male leopards (Bailey 1993) countered the effect of increased vegetation density and cover.

Apart from temporal patters in failure rates, our results indicate that location failures are spatially clustered for three of our five study animals. This result can, however, be expected since the sex of the leopard effects its behaviour (Bailey 1993), and time of day effects its habitat selection and behaviour at that given time. Therefore, location failures could more likely occur at certain areas in an animals' home range. For two leopards, the location failures were not significantly different from a random distribution, which suggests that probability of failure was less affected by the area. This could happen when features affecting probability of failure are evenly distributed throughout the animal's home range.

\section{CONCLUSIONS}

We found both temporal and spatial patterns in the probability of location failures and also differences between males and females. Our results generally suggest that animal behaviour such as habitat selection and temporal patterns in activity is influencing GPS acquisition efficiency in this species. This calls for caution when using GPS data to estimate variables such as range use and habitat selection, and we suggest that appropriate measures should be taken to minimize the potentially biased results from GPS collars, for instance through sample weighing or iterative simulations. 


\section{ACKNOWLEDGEMENTS}

We thank Craig Tambling and Guy Balme for comments on the manuscript. Funding was provided by Jobedi Game Lodge, the Michael A. \& Pamela S. Came Foundation (U.S.A.) and the St Diererampen Fonds (Holland).

\section{REFERENCES}

ANDERSON, C.R. \& LINDZEY, F.G. 2003. Estimating cougar predation rates from GPS location clusters. J. Wildlife Manage. 67: 307-316.

BAILEY, T.N. 1993. The African leopard: ecology and behaviour of a solitary felid. Columbia University Press, New York.

BATSCHELET, E. 1981. Circular statistics in biology. Academic Press, London.

BOLKER, B.M., BROOKS, M., CLARK, C.J., GEANGE, S.W., POULSEN, J.R., STEVENS, M.H.H. \& WHITE, J.S.S. 2008. Generalized linear mixed models: a guide for ecology and evolution. Trends Ecol. Evol.24: 127-135.

DE WET, T. 1993. Physical capture of carnivores. In: A.A. Mckenzie (Ed.), The capture and care manual. Capture, care, accommodation and transportation of wild African animals (pp. 255-262). The South African Veterinary Foundation, Pretoria.

CAIN, J.W., KRAUSMAN, P.R., JANSEN, B.D. \& MORGART, J.R. 2005. Influence of topography and GPS fix interval on GPS collar performance. Wildlife Soc. B. 33(3): 926-934.

CLARK, P.J., \& EVANS, F.C. 1954: Distance to nearest neighbour as a measure of spatial relationships in populations. Ecology 35: 445-453.

D'EON, R.G. \& DELPARTE, D. 2005. Effects of radiocollar position and orientation on GPS radio-collar performance, and the implications of PDOP in data screening. J. Appl. Ecol. 42: 383-388.

D'EON, R.G., SERROUYA, R., SMITH, G. \& KOCHANNY, C.O. 2002. GPS radiotelemetry error and bias in mountainous terrain. Wildlife. Soc. B. 30: 430-439.

DOUGLAS-HAMILTON, I. 1998. Tracking African elephants with a global positioning system (GPS) radio collar. Pachyderm 25: 81-92.

FRAIR, J.L., NIELSEN, S.E., MERRILL, E.H., LELE, S.R., BOYCE, M.S., MUNRO, R.H.M., STENHOUSE, G.B. \& BEYER, H.L. 2004. Removing GPS collar bias in habitat selection studies. J. Appl. Ecol. 41: 201-212.

GAU, R.J., MULDERS, R., CIARNIELLO, L.M., HEARD, D.C., CHETKIEWICZ, C.L.B., BOYCE, M., MUNRO, R., STENHOUSE, G., CHRUSZCZ, B., GIBEAU, M.L., MILAKOVIC, B. \& PARKER, K.L. 2004. Uncontrolled field performance of Televilt GPS-Simplex ${ }^{\oplus}$ collars on grizzly bears in western and northern Canada. Wildlife Soc. B. 32: 693-701.

GRIMBEEK, A.M. 1992. The ecology of the leopard (Panthera pardus) in the Waterberg. M.Sc. thesis, University of Pretoria.

JANEAU, G., ADRADOS, C., JOACHIM, J., GENDNER, J. \& PÉPIN, D. 2004. Performance of differential GPS collars in temperate mountain forest. C. R. Biol. 327: 1143-1149.

MERRILL, S.B. \& MECH, D.L. 2003. The usefulness of GPS telemetry to study wolf circadian and social activity. Wildlife Soc. B. 31: 947-960.

MOEN, R., PASTOR, J. \& COHEN, Y. 2001. Effects of animal activity on GPS telemetry location attempts. Alces 37: 207-210.

MUCINA, L. \& RUTHERFORD, M.C. (Eds) 2006. The vegetation of South Africa, Lesotho and Swaziland. Strelitzia 19. South African National Biodiversity Institute, Pretoria.

OBBARD, M.E., POND, B.A. \& PERERA, A. 1995. Preliminary evaluation of GPS collars for analysis of habitat use and activity patterns of black bears. Ursus 10: 209-217.

PRIEDE, I.G. \& SWIFT, S.M. 1992. Wildlife telemetry: remote monitoring and tracking of wild animals. Ellis Horwood, Chichester.

RAHIMI, S. \& OWEN-SMITH, N. 2007. Movement patterns of sable antelope in the Kruger National Park from GPS/GSM collars: a preliminary assessment. S. Afr. J. Wildl. Res. 37(2): 143-151.

REMPEL, R.S., RODGERS, A.R. \& ABRAHAM, K.F. 1995. Performance of a GPS Animal Location System under boreal forest canopy. J. Wildlife Manage. 59(3): 543-551.

RON, M., PASTOR, J., COHEN, Y. \& SCHWARTZ, C.C. 1996. Effects of moose movement and habitat use on GPS collar performance. J. Wildlife Manage. 60: 659-668.

SKINNER, J.D. \& CHIMIMBA, C.T. 2005. The mammals of the southern African subregion. Cambridge University Press, Cambridge.

Corresponding Editor: G.I.H. Kerley 